\title{
A bibliometric analysis of testicular germ cell tumor research from 2000 to 2020
}

\author{
Chengyuan Wang ${ }^{1 \#}$, Lin Tong ${ }^{2 \#}$, Jiaxi Yao ${ }^{1}$, Zuyu Sun ${ }^{1}$, Xinyu Zhang ${ }^{3}$, Tao Liu ${ }^{1}$, Lei Yin ${ }^{1}$ \\ ${ }^{1}$ Department of Urology, The First Affiliated Hospital of China Medical University, Shenyang, China; ${ }^{2}$ Clinical Nursing Section, The First Affiliated \\ Hospital of China Medical University, Shenyang, China; ${ }^{3}$ Department of Pulmonary Critical Care Medicine, The First Affiliated Hospital of China \\ Medical University, Shenyang, China \\ Contributions: (I) Conception and design: L Yin, T Liu; (II) Administrative support: T Liu; (III) Provision of study materials or patients: C Wang, X \\ Zhang; (IV) Collection and assembly of data: C Wang, L Tong; (V) Data analysis and interpretation: C Wang, L Tong; (VI) Manuscript writing: All \\ authors; (VII) Final approval of manuscript: All authors. \\ \#These authors contributed equally to this work. \\ Correspondence to: Tao Liu, Lei Yin. Department of Urology, The First Affiliated Hospital of China Medical University, 155 Nanjing Bei Street, \\ Shenyang, China. Email: cmuliu2016@163.com; junecmu2019@163.com.
}

\begin{abstract}
Background: Thousands of papers on testicular germ cell tumor (TGCT) have been published over the past two decades. This study aimed to assess the key topics and future trends in TGCT research from a comprehensive perspective.

Methods: All literature defined as review and article type on TGCT published between 2000 and 2020 was identified and retrieved from the Web of Science Core Collection (WoSCC) database. Bibliometric analysis was conducted by the online analysis platform and VOSviewer (version 1.6.16). The key directions and future trends in the research field of TGCT were evaluated using Bibliographic Item Co-occurrence Matrix Builder (version 2.0) and gCLUTO software.

Results: Ultimately, a total of 4,550 papers between 2000 and 2020 were included in the field of TGCT. The leadership of the United States in global TGCT research with 1,549 publications during the last two decades was obvious. The Indiana University was the most productive institution with 360 publications, and it was also the institution most frequently involved in research cooperation. Fournal of Urology published the highest number of publications on TGCT. Looijenga LHJ, Bokemeyer C, Ulbright TM, Sheinfeld $\mathrm{J}$ and Dieckmann KP were the top productive contributors to TGCT research. Further, five research hotspots have been identified: (I) epidemiology of TGCT; (II) TGCT-related infertility; (III) pathological classification with TGCT; (IV) management options for TGCT; and (V) Prevention of cancer metastasis in TGCT patients.

Conclusions: During the last two decades, the United States was a global leader, and research hotspots included epidemiology, male infertility, pathology, and therapy in the field of TGCT. Furthermore, the genetics mechanisms and cisplatin resistance will remain hotspots in future TGCT research.
\end{abstract}

Keywords: Testicular germ cell tumor (TGCT); bibliometric analysis; research hotspots

Submitted Mar 08, 2021. Accepted for publication Jul 14, 2021.

doi: $10.21037 /$ tcr-21-412

View this article at: https://dx.doi.org/10.21037/tcr-21-412

\section{Introduction}

Testicular germ cell tumor (TGCT) is the most common cancer among young adult men (1), and its incidence has been on the rise worldwide over the last two decades $(2,3)$.
Cryptorchidism is the most common risk factor associated with TGCT, increasing the risk of cancer by nearly five times (4). Protecting reproductive function, preventing mental fatigue and anxiety, and improving the quality of life 
are all crucial issues in young men with TGCT. During the last two decades, substantial advancing has been made in the field of TGCT research regarding genetic susceptibility, diagnostics, therapeutics and epidemiology $(4,5)$. However, few scientific reports can help researchers obtain an intuitive overview in the field of TGCT research.

Bibliometric analysis, a novel comprehensive analysis method, was used to access contributions qualitatively and quantitatively in a specific field, including countries, institutions, journals, and authors. Bibliometric analysis also can predict research hotspots and future trends through data visualization (6-8). In 2013, Nason described the top 100 cited articles in urology and analyzed the key topics and advances in urology (9). However, there is no bibliometric study to evaluate hotspots and summarize progress in TGCT research field over the past 20 years.

In our study, a bibliometric analysis of TGCT was performed based on relevant literature from 2000 to 2020 . Bibliometric indicators were comprehensively evaluated and visualized, including the number of annual publications, the contributions of countries, institutions, authors and journals. International cooperation and keyword cooccurrence visualization analysis were also performed. Furthermore, research hotspots and future trends in TGCT field were evaluated via the overlay map of co-occurring keywords and bi-clustering visualization analysis.

\section{Methods}

\section{Source database and retrieval strategy}

The Web of Science Core Collection (WoSCC) is one of the most authoritative and influential databases of scientific literature. In our study, all data was retrieved, filtered, and downloaded through the WoSCC database. The following search strategy was used: TS = Testicular germ cell tumor.

\section{Screening criteria and data downloads}

The timespan in the present study was set from 2000 to 2020. The language type was limited as English. For publication types, only articles and reviews were included, and all other types were excluded in the study. WoSCC data including journals, titles, abstracts, keywords, author information, and cited references were downloaded in TXT format. In case of the bias caused by frequent update of the WoSCC database, data retrieval and download were performed on the same day (January 23, 2021). Two independent authors (Chengyuan Wang and Lin Tong) finished the systematic literature search and had an agreement of $99 \%$, showing significant consistency (10).

\section{Statistical analysis}

In our study, a comprehensive description of various publishing characteristics is provided qualitatively and quantitatively, including countries, institutions, authors, journals, H-index and impact factors (IFs). H-index was defined as the number of papers with citation number $\geq h$ and is considered to be an important indicator for assessing both the productivity and impact of the published work of scientists, journals, or countries (11). IFs were obtained from the latest version of Journal Citation Reports (JCR) to assess the impact of journals (12). The VOSviewer (version 1.6.15) and online platform of literature metrology analysis (http://bibliometric.com/) were used to perform bibliometric analysis. VOSviewer was used to visualize the networks such as institution, journal, author, co-citation, and the keywords (13). Overlay visualization maps were also conducted using VOSviewer to show the timescale of the TGCT research. The international collaboration network between countries/regions was performed using the online bibliometric analysis platform. The Microsoft Excel (version 2016) were used to evaluate the impact of countries/regions, institutions, authors, and journals. The downloaded data from the WoSCC database were imported into Bibliographic item co-occurrence matrix builder (BICOMB) to build a binary matrix of keyword-article (14). Furthermore, graphical clustering toolkit (gCLUTO) (version 1.0) software was used to perform bi-clustering visualization analysis, and to build three-dimensional mountain maps and heat maps based on the binary matrix of keyword-article (14).

\section{Results}

\section{Distribution of annual publications}

Based on the Screening criteria, a total of 4,550 papers (3,881 articles and 669 reviews) from the 20-year period were ultimately obtained (Figure 1). Figure 2 showed the growth trend of annual publications in TGCT research field, from 152 in 2010 to 263 in 2020. According to the WoSCC database, the 4,550 papers were cited 122,273 times, 


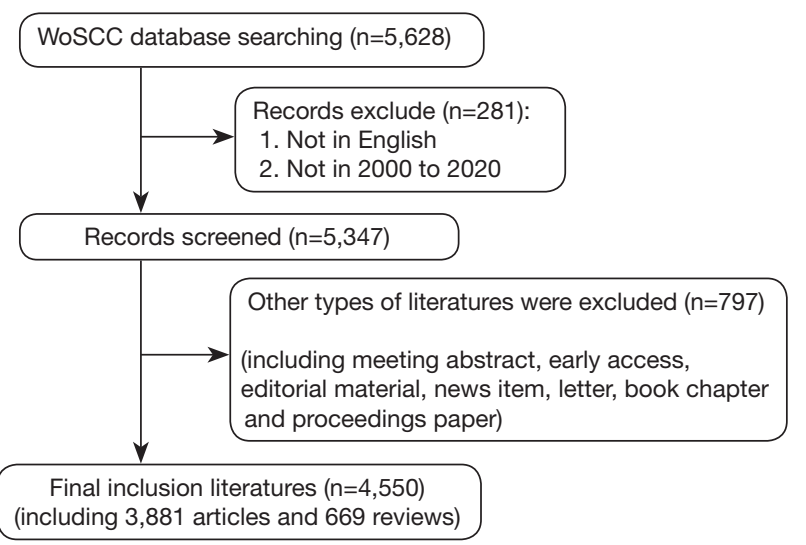

Figure 1 Flowchart diagram of publications filtration. WoSCC, Web of Science Core Collection.

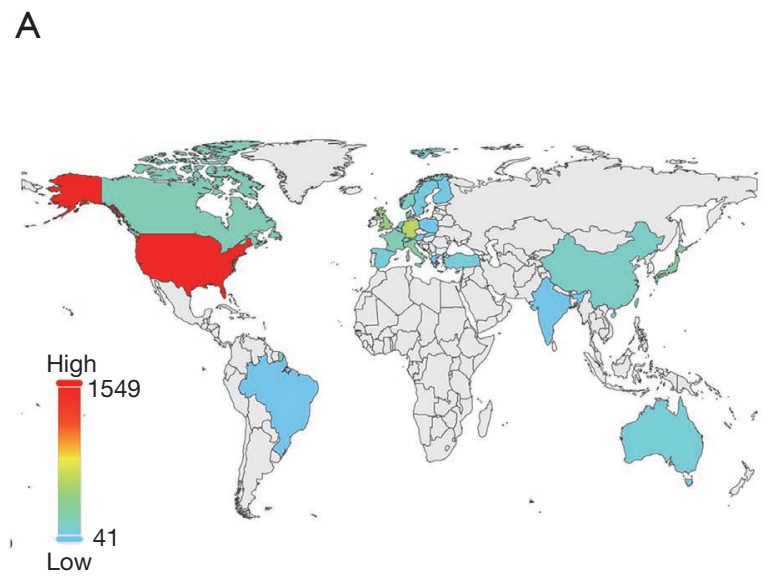

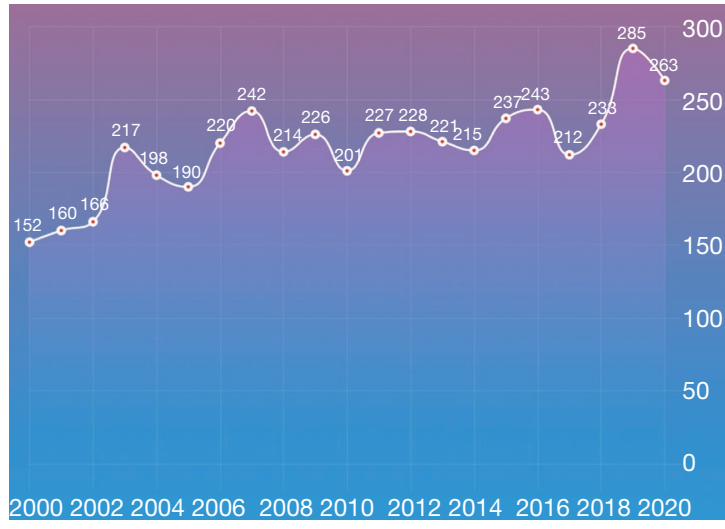

Figure 2 The growth trends of the publications on TGCT from 2000 to 2020. TGCT, testicular germ cell tumor.

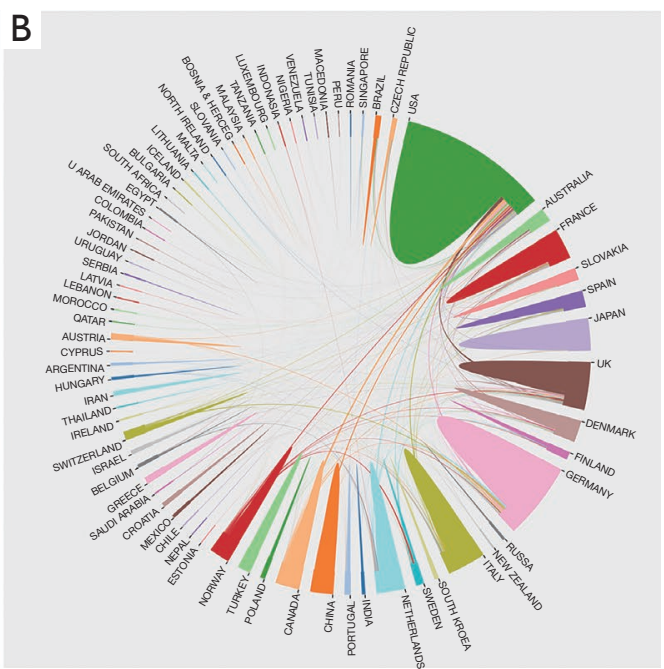

Figure 3 The publications output of countries or regions on TGCT. (A) The world map of distribution of TGCT publications. (B) The cooperation network of countries or regions in the field of TGCT research. TGCT, testicular germ cell tumor.

with an average of 26.87 times in each paper.

\section{Analysis of countries and institutions}

From 2000 to 2020, 86 countries or regions contributed to publications associated with TGCT. According to the WoSCC database, the top 25 most productive countries or regions are shown on the map to explore the worldwide geographic distribution in TGCT research field (Figure 3A). The countries or regions ranked $1-10$ are presented as numbers in Table 1. Among them, the United States was the most productive country in the field of TGCT, with 1,549 papers published, followed by Germany $(n=614)$,
England ( $\mathrm{n}=430)$, Japan ( $\mathrm{n}=345)$, Italy $(\mathrm{n}=324)$, Netherlands $(n=298)$, France $(n=247)$, Canada $(n=240)$, Denmark $(\mathrm{n}=236)$ and China $(\mathrm{n}=184)$. As shown in Figure $3 B$, close cooperation between countries or regions was extremely popular over the past 20 years. Furthermore, the international cooperation network analysis showed that the United States was the country most actively participated in the international cooperation.

As depicted in Table 2, Indiana University was the most productive institution, with 360 papers published, followed by the Memorial Sloan-Kettering Cancer Center $(\mathrm{n}=247)$, National Cancer Institute $(\mathrm{n}=160)$, Institute for Cancer Research ( $\mathrm{n}=156)$, University of Toronto $(\mathrm{n}=156)$, 
The University of Texas MD Anderson Cancer Center $(\mathrm{n}=141)$, University of Pennsylvania $(\mathrm{n}=131)$, Comenius University ( $\mathrm{n}=117)$, Rigshospitalet Kopenhagen ( $\mathrm{n}=115)$ and Norwegian Radium Hospital $(\mathrm{n}=113)$. The network

Table 1 The top 10 most productive countries or regions in the field of TGCT research

\begin{tabular}{llcc}
\hline Rank & Country/region & Records & $\begin{array}{c}\text { Percentage. } \\
(\mathrm{N} / 4,550), \%\end{array}$ \\
\hline 1 & USA & 1,549 & 34.044 \\
2 & Germany & 614 & 13.495 \\
3 & England & 430 & 9.451 \\
4 & Japan & 345 & 7.582 \\
5 & Italy & 324 & 7.121 \\
6 & The Netherlands & 298 & 6.549 \\
7 & France & 247 & 5.429 \\
7 & Canada & 240 & 5.275 \\
7 & Denmark & 236 & 5.187 \\
10 & China & 184 & 4.044 \\
\hline
\end{tabular}

knowledge map among institutions was generated via VOSviewer, and 50 was set to the threshold as the minimum number of papers, while 500 was set to the threshold as the minimum number of citations. Ultimately, as shown in Figure 4, 16 out of the 3,977 institutions were identified. In addition, Indiana University cooperated with nearly every influential scientific institution in the field of TGCT during the last 20 years.

\section{Analysis of journals}

As shown in Table 3, the top 10 most productive journals, which published 926 papers, accounting for $20.35 \%$ of the total publications in the field of TGCT research. Fournal of Urology $(\mathrm{n}=136)$, Urology $(\mathrm{n}=120)$, and Fournal of Clinical Oncology $(\mathrm{n}=108)$ were the top three journals which had the largest number of publications in the field of TGCT research. Fournal of Clinical Oncology, Fournal of Urology, and European Urology were the top three journals which had the largest number of citations (4,026 vs. 2,327 vs. 2,190 citations, respectively). However, Fournal of Clinical Oncology, European Urology, and Annals of Oncology had the largest number of average citations per paper (37.28 vs. 25.76

Table 2 The top 10 most productive institutions in the field of TGCT research

\begin{tabular}{|c|c|c|c|c|c|c|c|}
\hline Rank & Institutions & $\begin{array}{l}\text { Article } \\
\text { counts }\end{array}$ & $\begin{array}{c}\text { Total number of } \\
\text { citations }\end{array}$ & $\begin{array}{l}\text { Average number } \\
\text { of citations }\end{array}$ & $\begin{array}{l}\text { Total number of } \\
\text { first author }\end{array}$ & $\begin{array}{c}\text { Total number of first } \\
\text { author citations }\end{array}$ & $\begin{array}{l}\text { Average number of } \\
\text { first author citations }\end{array}$ \\
\hline 1 & Indiana University & 360 & 5,893 & 16.37 & 166 & 2,474 & 14.90 \\
\hline 3 & $\begin{array}{l}\text { National Cancer } \\
\text { Institute }\end{array}$ & 160 & 2,715 & 16.97 & 75 & 1,328 & 17.71 \\
\hline 4 & $\begin{array}{l}\text { Institute for Cancer } \\
\text { Research }\end{array}$ & 156 & 4,782 & 30.65 & 53 & 1,716 & 32.38 \\
\hline 5 & University of Toronto & 156 & 2,289 & 14.67 & 36 & 470 & 13.06 \\
\hline 6 & $\begin{array}{l}\text { The University of Texas } \\
\text { MD Anderson Cancer } \\
\text { Center }\end{array}$ & 141 & 1,151 & 8.16 & 40 & 156 & 3.9 \\
\hline 8 & Comenius University & 117 & 730 & 6.24 & 35 & 196 & 5.6 \\
\hline 9 & $\begin{array}{l}\text { Rigshospitalet } \\
\text { Kopenhagen }\end{array}$ & 115 & 1,961 & 17.05 & 52 & 974 & 18.73 \\
\hline 10 & $\begin{array}{l}\text { Norwegian Radium } \\
\text { Hospital }\end{array}$ & 113 & 3,545 & 31.37 & 32 & 719 & 22.47 \\
\hline
\end{tabular}



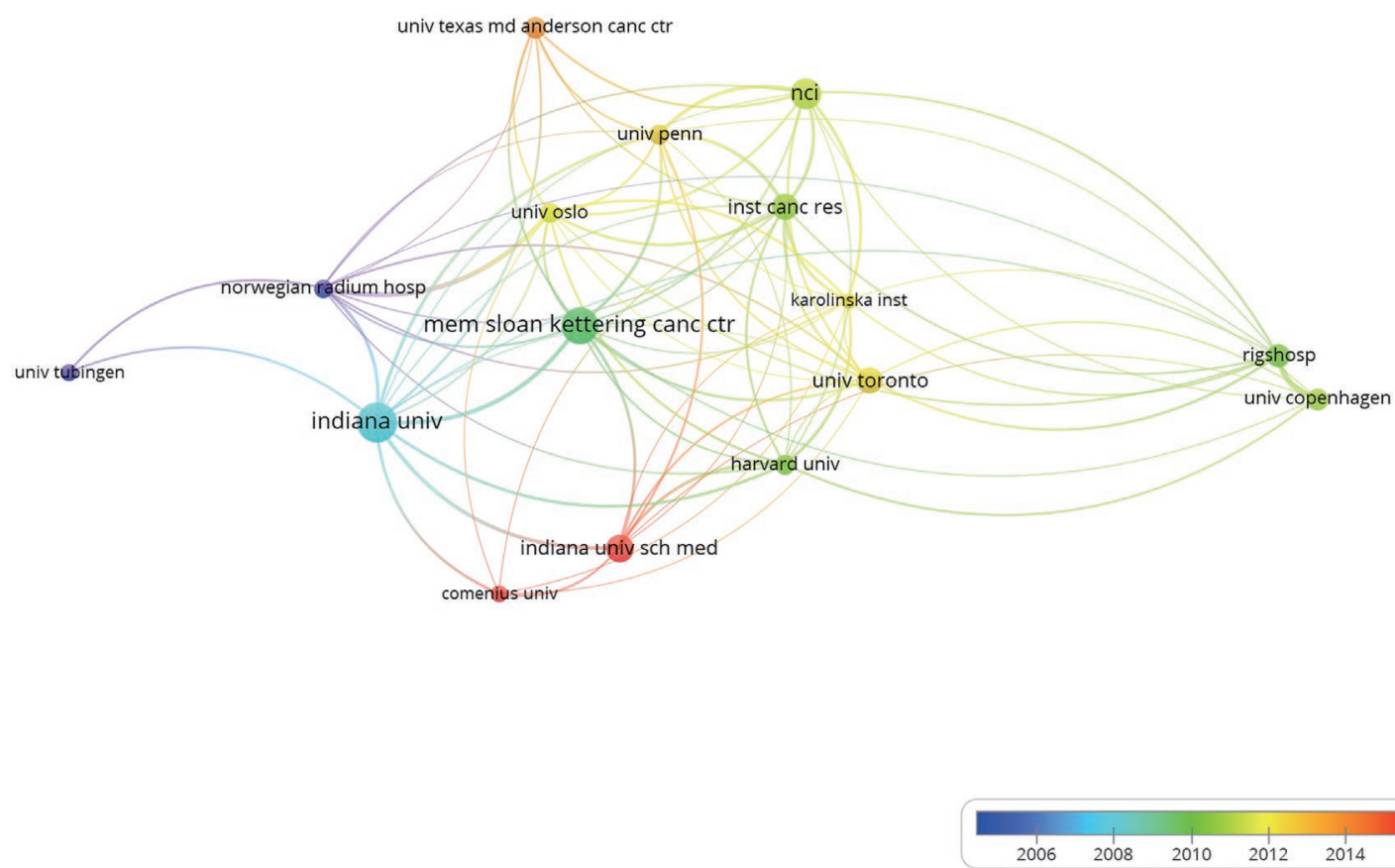

Figure 4 Co-authorship overlay visualization network of institutions in the field of TGCT research. TGCT, testicular germ cell tumor.

Table 3 The top 10 most active journals in the field of TGCT research

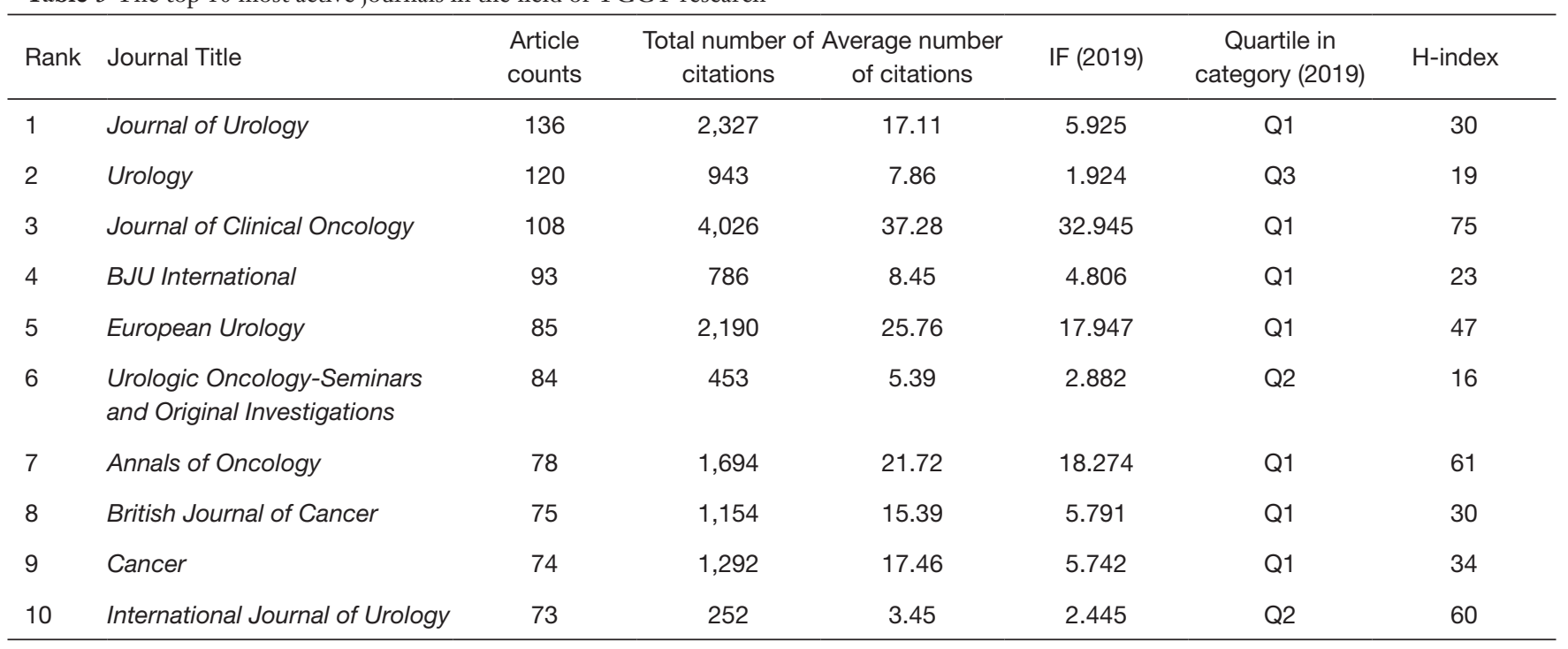

IF, impact factor; H-index, Hirsch index; JCR, Journal Citation Reports.

vs. 21.27 times, respectively). Fournal of Clinical Oncology, Annals of Oncology, and European Urology had the highest IFs in the latest version of JCR (32.945 vs. 18.274 vs. 17.947, respectively). Fournal of Clinical Oncology had the highest $\mathrm{H}$-index of any journals in the field of TGCT research, with a score of 75. Among the top 10 journals with the largest number of published papers, Fournal of Urology, Fournal of Clinical Oncology, BfU International, European Urology, Annals of Oncology, British Fournal of Cancer, and Cancer were identified as Q1 based on the latest version of JCR standards 
Table 4 The top 10 high-cited papers in the field of TGCT research from 2000 to 2020

\begin{tabular}{|c|c|c|c|c|c|}
\hline Rank & Title & Authors & Year & Journal & $\begin{array}{c}\text { Total } \\
\text { citations }\end{array}$ \\
\hline 1 & $\begin{array}{l}\text { Cisplatin in cancer therapy: Molecular mechanisms of } \\
\text { action }\end{array}$ & Dasari, Shaloam, et al. & 2014 & $\begin{array}{l}\text { European Journal of } \\
\text { Pharmacology }\end{array}$ & 1,696 \\
\hline 2 & $\begin{array}{l}\text { Testicular dysgenesis syndrome: an increasingly common } \\
\text { developmental disorder with environmental aspects }\end{array}$ & Skakkebaek NE, et al. & 2001 & Human Reproduction & 1,411 \\
\hline 4 & $\begin{array}{l}\text { Proliferation and functional maturation of Sertoli cells, and } \\
\text { their relevance to disorders of testis function in adulthood }\end{array}$ & Sharpe RM, et al. & 2003 & Reproduction & 763 \\
\hline 5 & $\begin{array}{l}\text { The } 2016 \text { WHO Classification of Tumours of the Urinary } \\
\text { System and Male Genital Organs-Part A: Renal, Penile, } \\
\text { and Testicular Tumours }\end{array}$ & Moch Holger, et al. & 2016 & European Urology & 740 \\
\hline 7 & Testicular germ-cell tumours in a broader perspective & Oosterhuis JWS, et al. & 2005 & Nature Reviews Cancer & 608 \\
\hline 8 & $\begin{array}{l}\text { Second cancers among 40,576 testicular cancer patients: } \\
\text { Focus on long-term survivors }\end{array}$ & Travis LB, et al. & 2005 & $\begin{array}{l}\text { JNCl-Journal of The } \\
\text { National Cancer Institute }\end{array}$ & 545 \\
\hline 9 & $\begin{array}{l}\text { Sertoli-Sertoli and Sertoli-germ cell interactions and their } \\
\text { significance in germ cell movement in the seminiferous } \\
\text { epithelium during spermatogenesis }\end{array}$ & Mruk DD, et al. & 2004 & Endocrine Reviews & 533 \\
\hline 10 & $\begin{array}{l}\text { Gene expression patterns in human embryonic stem cells } \\
\text { and human pluripotent germ cell tumors }\end{array}$ & Sperger JM, et al. & 2003 & $\begin{array}{l}\text { Proceedings of the National } \\
\text { Academy of Sciences of the } \\
\text { United States of America }\end{array}$ & 514 \\
\hline
\end{tabular}

(Table 3). In addition, Table 4 listed the top 10 most highly cited papers and these papers had great influence in the field of TGCT research over the last 20 years.

\section{Analysis of authors}

The top 10 most productive authors in the field of TGCT research were also evaluated (Table 5). Among them, Looijenga LHJ from the Princess Máxima Center for Pediatric Oncology in Netherlands ranked first and published 130 papers over the last 20 years. Bokemeyer C from the Department of Oncology, Hematology and Bone Marrow Transplantation with Division of Pneumology, University Medical Center Hamburg-Eppendorf in Germany was the second most productive author in the field of TGCT research ( $n=92)$. Furthermore, Looijenga LHJ, Oosterhuis JW, and Bokemeyer C were the top three authors who had the highest number of citations $(3,854 \mathrm{vs}$. 2,946 vs. 2,877 times, respectively). VOSviewer software was used to generate the co-authorship overlay visualization network, and the threshold was set to 20 as the minimum number of published papers by authors. Finally, as shown in Figure 5, 33 authors who met the screening criteria were identified, of which Sheinfeld J, Motzer RJ, Bosl GJ, and Carver BS were shown to cooperate closely. VOSviewer software was also used to generate the citation overlay visualization map, and the threshold was set to 300 as the minimum number of total citations from authors. Finally, 33 authors were identified, of which Looijenga LHJ, Bokemeyer C, Ulbright TM, Sheinfeld J and Dieckmann $\mathrm{KP}$ were shown to make significant contributions to the field of TGCT research (Figure 5B).

\section{Analysis of research hotspots}

In our study, the keywords with the highest frequency of occurrence were identified from the included publications and the top 39 most frequent keywords are shown in Table 6, with an appearance of more than 30 times. The relationship between the extracted high-frequency keywords and 
Table 5 The top 10 most productive authors in the field of TGCT research

\begin{tabular}{|c|c|c|c|c|c|c|c|c|}
\hline Rank & Author & $\begin{array}{l}\text { Article } \\
\text { counts }\end{array}$ & $\begin{array}{l}\text { Total number } \\
\text { of citations }\end{array}$ & $\begin{array}{l}\text { Average number } \\
\text { of citations }\end{array}$ & $\begin{array}{l}\text { First author } \\
\text { counts }\end{array}$ & $\begin{array}{l}\text { First author } \\
\text { citation counts }\end{array}$ & $\begin{array}{l}\text { Corresponding } \\
\text { author counts }\end{array}$ & $\begin{array}{l}\text { Corresponding author } \\
\text { citation counts }\end{array}$ \\
\hline 1 & Looijenga LHJ & 130 & 3,854 & 29.65 & 15 & 671 & 44.73 & 62 \\
\hline 3 & Fossa SD & 85 & 2,509 & 29.52 & 6 & 189 & 31.5 & 11 \\
\hline 6 & Skakkebaek NE & 78 & 2,168 & 27.79 & 5 & 77 & 15.4 & 6 \\
\hline 7 & Oosterhuis JW & 74 & 2,946 & 39.81 & 7 & 491 & 70.14 & 6 \\
\hline 8 & McGlynn KA & 72 & 1,407 & 19.54 & 12 & 452 & 37.67 & 24 \\
\hline
\end{tabular}

publications was visualized using BICOMB. gCLUTO software was utilized for visual analysis and identification of clusters. Finally, the top 39 most frequent keywords were divided into 5 different clusters according bi-clustering analysis to identify the research hotspots in the field of TGCT research (Figure 6A). In addition, the 3-dimensional volcano map was generated for visualization of clustering results (Figure 6B).

Cluster 0: Epidemiology of TGCT.

Cluster 1: TGCT-related infertility.

Cluster 2: Pathological classification with TGCT.

Cluster 3: Management options for TGCT.

Cluster 4: Prevention of cancer metastasis in TGCT patients.

VOSviewer software was used to generate an overlay visualization network of keyword co-occurrence to explore the changes of research hotspots over the last 20 years, and our results indicated that the keywords "genome-wide association" and "cisplatin resistance" began to emerge in the last seven years in the field of TGCT research (Figure 7).

\section{Discussion}

In recent years, bibliometric analysis has been widely used in many scientific research fields, which can help researchers with different backgrounds to understand the research progress of a certain field and visualize the knowledge structure more intuitively. In addition, many indicators obtained from bibliometric analysis will give researchers an intuitive overview such as the most productive authors, milestone manuscripts, popular journals, research hotspots, and future trends (15-17). In the present study, we performed a comprehensive bibliometric analysis of global scientific publications in the field of TGCT research over the last 20 years.

The productivity and development of a specific field over a period of time can be reflected by the number of publications (18). A total of 4,550 publications, including 263 papers in 2020, were included in our study (Figures 1,2). Our results indicated that the number of publications was maintained at a substantial level over the last 20 years from 2000 to 2020, which also showed that TGCT was still a hot research field, and there may be more and more scientific problems waiting for scholars to explore in the field of TGCT research.

The number of publications is an important indicator to evaluate the scientific research level of a country or institution in a particular research field $(15,18,19)$. Our results indicated that the United States and Germany were the 2 largest contributors in terms of the number of publications over the last 20 years (Figure 3A, Table 1), highlighting their dominant impact in the field of TGCT research. Meanwhile, international cooperation analysis showed that the United States participated in the cooperation most frequently from 2000 to 2020, especially with the UK and Canada (Figure 3B). Furthermore, Indiana University was identified as the most productive institution over the last 20 years, and had the highest collaboration performance with almost all influential scientific institutions in the field of TGCT research, including Memorial 

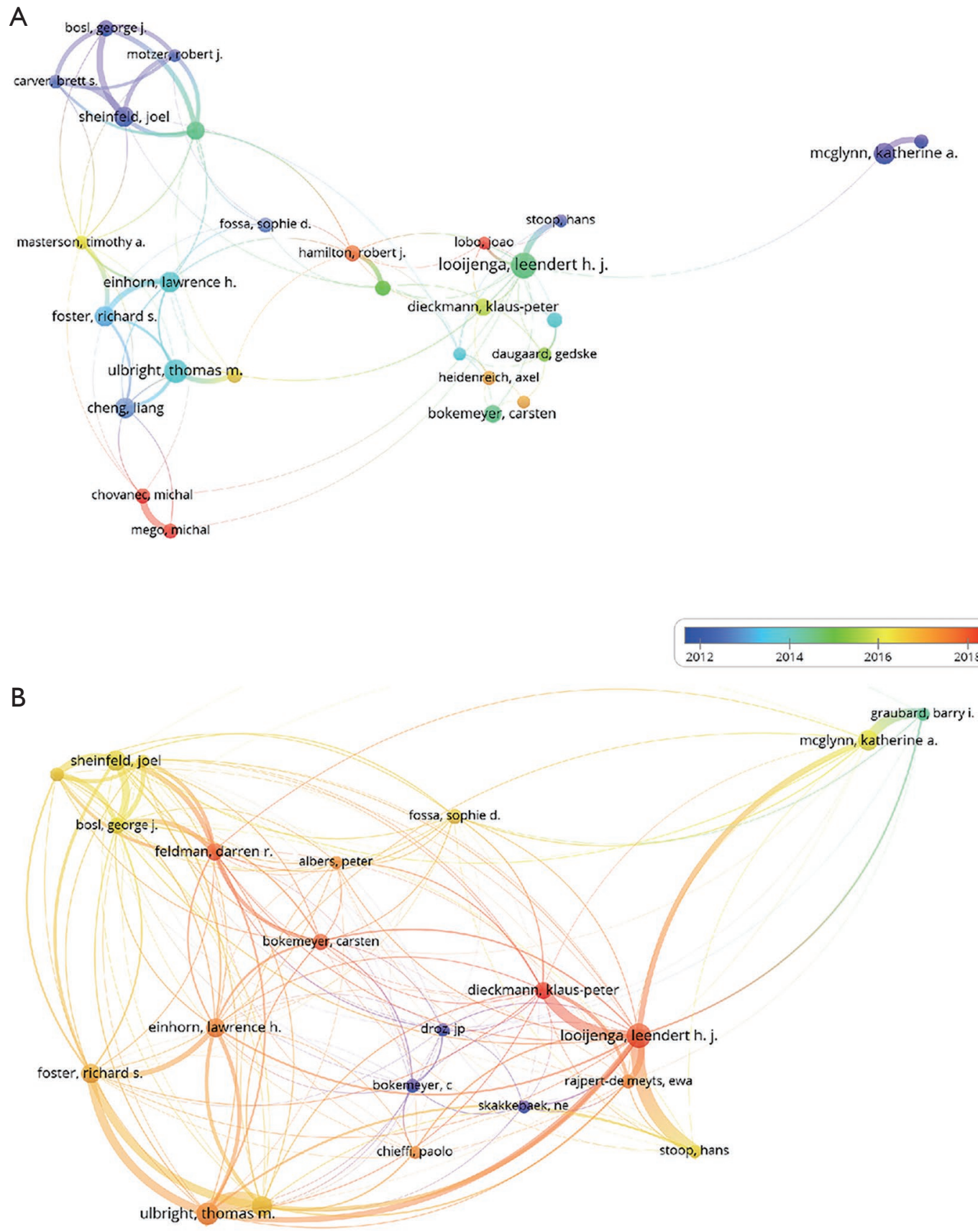

Figure 5 Co-authorship overlay visualization network of authors in the field of TGCT research. (A) Author co-authorship overlay visualization network. (B) Author co-citation overlay visualization network. TGCT, testicular germ cell tumor. 
Table 6 The high-frequency keywords in the field of TGCT research

\begin{tabular}{|c|c|c|c|}
\hline Number & Keywords & Frequency & $\%$ \\
\hline 1 & Testicular cancer & 968 & 5.5731 \\
\hline 2 & Germ cell tumor & 686 & 3.9496 \\
\hline 3 & Testis & 463 & 2.6657 \\
\hline 4 & Seminoma & 398 & 2.2914 \\
\hline 5 & Chemotherapy & 285 & 1.6409 \\
\hline 6 & Testicular germ cell tumor & 264 & 1.5199 \\
\hline 7 & Cancer & 139 & 0.8003 \\
\hline 8 & Teratoma & 138 & 0.7945 \\
\hline 9 & Cisplatin & 119 & 0.6851 \\
\hline 10 & Immunohistochemistry & 116 & 0.6679 \\
\hline 11 & Testis cancer & 108 & 0.6218 \\
\hline 12 & Surveillance & 99 & 0.5700 \\
\hline 13 & Spermatogenesis & 98 & 0.5642 \\
\hline 14 & Apoptosis & 98 & 0.5642 \\
\hline 15 & Germ cell & 96 & 0.5527 \\
\hline 16 & Non-seminoma & 92 & 0.5297 \\
\hline 17 & $\begin{array}{l}\text { Retroperitoneal lymph node } \\
\text { dissection }\end{array}$ & 88 & 0.5066 \\
\hline 18 & Embryonal carcinoma & 87 & 0.5009 \\
\hline 19 & Radiotherapy & 73 & 0.4203 \\
\hline 20 & Prognosis & 73 & 0.4203 \\
\hline 21 & $\begin{array}{l}\text { Non-seminomatous germ cell } \\
\text { tumor }\end{array}$ & 71 & 0.4088 \\
\hline 22 & Cryptorchidism & 70 & 0.4030 \\
\hline 23 & Germ cell cancer & 65 & 0.3742 \\
\hline 24 & Carcinoma in situ & 62 & 0.3570 \\
\hline 25 & Testicular tumor & 55 & 0.3167 \\
\hline 26 & Germinoma & 55 & 0.3167 \\
\hline 27 & Lymph node excision & 54 & 0.3109 \\
\hline 28 & Yolk sac tumor & 54 & 0.3109 \\
\hline 29 & Testicular neoplasm & 53 & 0.3051 \\
\hline 30 & Fertility & 52 & 0.2994 \\
\hline 31 & Survival & 51 & 0.2936 \\
\hline 32 & Infertility & 49 & 0.2821 \\
\hline 33 & Incidence & 46 & 0.2648 \\
\hline
\end{tabular}

Table 6 (continued)
Table 6 (continued)

\begin{tabular}{llcc}
\hline Number & Keywords & Frequency & $\%$ \\
\hline 34 & High-dose chemotherapy & 44 & 0.2533 \\
35 & Surgery & 39 & 0.2245 \\
36 & Epidemiology & 35 & 0.2015 \\
37 & P53 & 35 & 0.2015 \\
38 & Germ cell and embryonal & 34 & 0.1958 \\
39 & Ovary & 31 & 0.1785 \\
\hline
\end{tabular}

TGCT, testicular germ cell tumor.

Sloan-Kettering Cancer Center, the University of Texas MD Anderson Cancer Center, Harvard university and Norwegian Radium Hospital (Table 2, Figure 4). These results indicated that frequently collaborations between countries or institutions will be the future trend in the field of TGCT research.

Indicators from bibliometric analysis can provide a reliable reference for scientific researchers to manage their knowledge or submit their manuscripts $(20,21)$. As shown in Table 3, the top 10 most productive journals were all included in the category of "Urology" or "Oncology". Our results indicated that fournal of Urology had the largest number of TGCT research papers and Journal of Clinical Oncology had the largest number of total citations. Our results indicated that the largest number of cited publications was a review written by Shaloam Dasari and Paul Bernard Tchounwou from Cellomics and Toxicogenomics Research Laboratory, Jackson State University in the USA, and that "Cisplatin in cancer therapy: Molecular mechanisms of action", was a milestone in the field of TGCT research from 2000 to 2020 (22) (Table 4). These highly cited papers and active journals can provide a reliable reference for researchers and TGCT had a significant role in the fields of urology and oncology.

According to the WoSCC database, Looijenga, LHJ was the most productive researcher and had the highest number of total citations in the field of TGCT research (Table 5). Furthermore, Looijenga LHJ, Bokemeyer C, Ulbright TM, Sheinfeld J and Dieckmann KP cooperated closely and published a considerable number of highly cited publications (Figure $5 A, B$ ). Thus, they can be recognized as leaders in the field of TGCT research.

Considering the heterogeneity of the TGCT research field, we divided the highly frequently keywords into 5 clusters via BICOMB and gCLUTO software (Figure 6). 


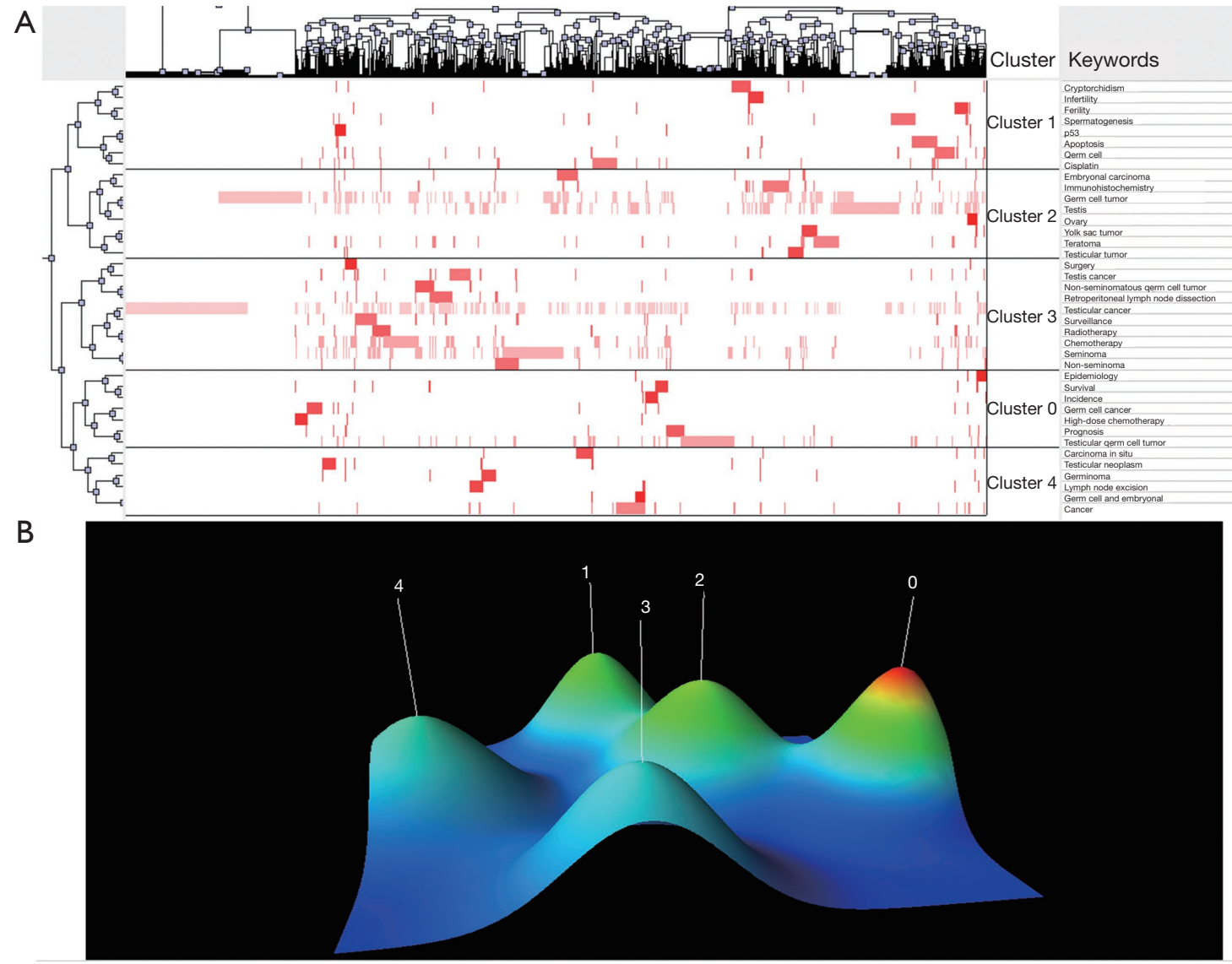

Figure 6 Research hotspots analysis in the field of TGCT research. (A) The visualized matrix of the highly frequent keywords base on biclustering analysis. (B) The volcano visualization map of the highly frequent keywords base on bi-clustering analysis in the field of TGCT research. TGCT, testicular germ cell tumor.

Cluster 0 is related to epidemiology of TGCT. In Western countries, TGCT is the most common cancer among men aged 14 to 44 (1). It is reported that Caucasians have an increase morbidity by 3-6\% per year in TGCT (23). Fortunately, the disease-specific survival after 15-year was $99.3 \%$ for patients initially diagnosed with stage I seminoma (24). Cluster 1 is related to TGCT-related infertility. TGCT patients have high risks of male infertility due to the decrease of sperm concentration, the decrease of total sperm motility and the increase of morphological alterations $(25,26)$. Because the fertility status of TGCT patients after treatment is difficult to predict, researchers consider it is necessary for extracting testicular sperm and cryopreservation of spermatozoa (27). Cluster 2 is related to pathological classification with TGCT. TGCT are mainly divided into seminoma, which resemble primordial germ cells, and non-seminoma, which are either embryonal carcinoma or yolk sac tumor (28). Around $15 \%$ of the TGCT is a mixture of seminoma and non-seminoma (29). Cluster 3 is related to management options for TGCT. After orchidectomy, management options for early-stage TGCT include active surveillance, primary chemotherapy and retroperitoneal lymph node dissection (RPLND), are helpful to reduce the long-term morbidity (30). In addition, patients are highly curable due to excellent cisplatin sensitivity of TGCT. However, approximately $10-20 \%$ of TGCT patients with cancer metastasis cannot be cured by cisplatin-based chemotherapy (31). Cluster 4 is related to prevention of cancer metastasis in TGCT patients. RPLND has played an indispensable role in the management of male metastatic TGCT for decades. The aim of RPLND is to remove lymph nodes from the primary retroperitoneal landing site of TGCT, commonly accomplished by using a split-and-roll technique to remove tissue surrounding 


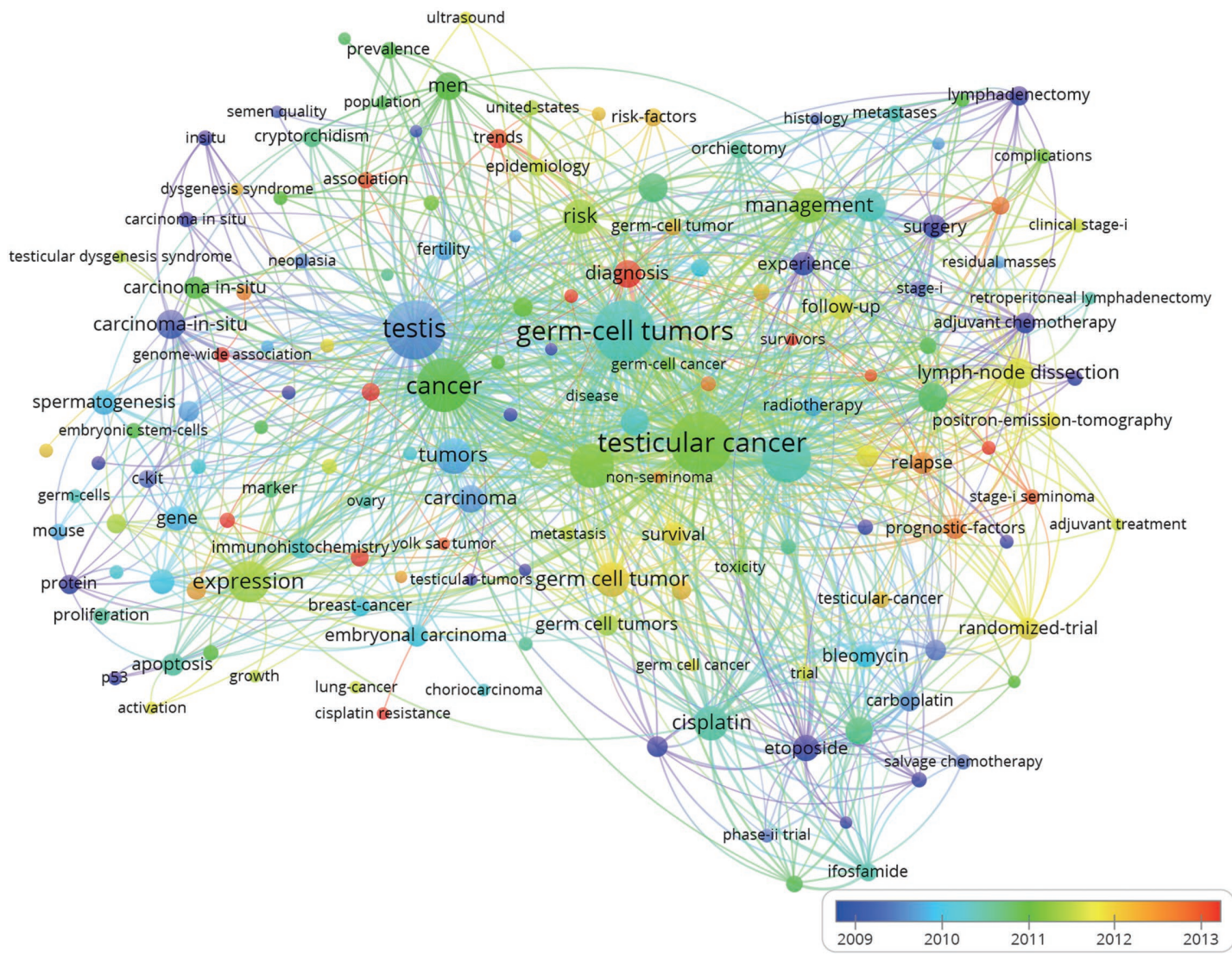

Figure 7 Co-occurrence overlay visualization network of keywords.

great vessels $(32,33)$. Whether TGCT or a metastatic setting, current guidelines should be strictly followed in TGCT patients to improve the cure rates. Exploring the combination of chemotherapy and targeted drugs is a major challenge for researchers and doctors.

The overlay network of keyword co-occurrence visualization analysis is a widely accepted analysis method to identify research hotspots and predict research trends (34). The keywords such as "genome-wide association" and "cisplatin resistance" appeared frequently in the last seven years, indicating that the genetics mechanisms and cisplatin resistance will continue to be research hotspots in the near future. Based on genome wide association studies (GWAS), Substantial advancing has been made in understanding genetic susceptibility in the last decade (35). GWAS have identified multiple novel susceptibility loci and provided a comprehensive understanding of the underlying genetic architecture of TGCT $(36,37)$. TGCT show excellent sensitivity to cisplatin-based chemotherapy and the emergence of cisplatin resistance is the major cause of treatment failure and death in TGCT patients $(29,38)$. The molecular mechanisms of cisplatin resistance in TGCT include the hyperactivity of PI3K/AKT/mTOR pathway, down-regulation of OCT4, and upregulation of MDM2 (31). Exploring the molecular mechanisms of cisplatin resistance is helpful to provide novel therapeutic targets, and a large number of clinical trials are needed to explore new therapeutic strategies in the future.

\section{Conclusions}

In our study, a comprehensive bibliometric analysis was performed for the first time to reveal the development of TGCT research. Research hotspots analysis suggested that genetics mechanisms and cisplatin resistance of TGCT will remain research hotspots in the next few years. International collaboration was common from 2000 to 2020, which may help researchers make a breakthrough in the near future. Our study provided a new perspective for TGCT research and may have a beneficial effect for further research in the 
diagnosis, treatment, and etiology of this condition.

\section{Acknowledgments}

Funding: Our study was funded by The Education Department of Liaoning Province (FWZR2020003).

\section{Footnote}

Peer Review File: Available at https://dx.doi.org/10.21037/ tcr-21-412

Conflicts of Interest: All authors have completed the ICMJE uniform disclosure form (available at https://dx.doi. org/10.21037/tcr-21-412). The authors have no conflicts of interest to declare.

Ethical Statement: The authors are accountable for all aspects of the work in ensuring that questions related to the accuracy or integrity of any part of the work are appropriately investigated and resolved.

Open Access Statement: This is an Open Access article distributed in accordance with the Creative Commons Attribution-NonCommercial-NoDerivs 4.0 International License (CC BY-NC-ND 4.0), which permits the noncommercial replication and distribution of the article with the strict proviso that no changes or edits are made and the original work is properly cited (including links to both the formal publication through the relevant DOI and the license). See: https://creativecommons.org/licenses/by-nc-nd/4.0/.

\section{References}

1. Ferlay J, Soerjomataram I, Dikshit R, et al. Cancer incidence and mortality worldwide: sources, methods and major patterns in GLOBOCAN 2012. Int J Cancer 2015;136:E359-86.

2. Bray F, Ferlay J, Soerjomataram I, et al. Global cancer statistics 2018: GLOBOCAN estimates of incidence and mortality worldwide for 36 cancers in 185 countries. CA Cancer J Clin 2018;68:394-424.

3. Global Burden of Disease Cancer Collaboration; Fitzmaurice C, Allen C, et al. Global, Regional, and National Cancer Incidence, Mortality, Years of Life Lost, Years Lived With Disability, and Disability-Adjusted Lifeyears for 32 Cancer Groups, 1990 to 2015: A Systematic Analysis for the Global Burden of Disease Study. JAMA
Oncol 2017;3:524-48.

4. Cheng L, Albers P, Berney DM, et al. Testicular cancer. Nat Rev Dis Primers 2018;4:29.

5. Rajpert-De Meyts E, McGlynn KA, Okamoto K, et al. Testicular germ cell tumours. Lancet 2016;387:1762-74.

6. Cooper ID. Bibliometrics basics. J Med Libr Assoc 2015;103:217-8.

7. Devos P, Ménard J. Trends in Worldwide Research in Hypertension Over the Period 1999-2018: A Bibliometric Study. Hypertension 2020;76:1649-55.

8. Wang $\mathrm{Y}$, Zhao N, Zhang X, et al. Bibliometrics Analysis of Butyrophilins as Immune Regulators 1992-2019 and Implications for Cancer Prognosis. Front Immunol 2020;11:1187.

9. Nason GJ, Tareen F, Mortell A. The top 100 cited articles in urology: An update. Can Urol Assoc J 2013;7:E16-24.

10. Landis JR, Koch GG. The measurement of observer agreement for categorical data. Biometrics 1977;33:159-74.

11. Hirsch JE. An index to quantify an individual's scientific research output. Proc Natl Acad Sci U S A 2005;102:16569-72.

12. Eyre-Walker A, Stoletzki N. The assessment of science: the relative merits of post-publication review, the impact factor, and the number of citations. PLoS Biol 2013;11:e1001675.

13. van Eck NJ, Waltman L. Citation-based clustering of publications using CitNetExplorer and VOSviewer. Scientometrics 2017;111:1053-70.

14. Li F, Li M, Guan P, et al. Mapping publication trends and identifying hot spots of research on Internet health information seeking behavior: a quantitative and co-word biclustering analysis. J Med Internet Res 2015;17:e81.

15. Glanville J, Kendrick T, McNally R, et al. Research output on primary care in Australia, Canada, Germany, the Netherlands, the United Kingdom, and the United States: bibliometric analysis. BMJ 2011;342:d1028.

16. Boudry C, Baudouin C, Mouriaux F. International publication trends in dry eye disease research: A bibliometric analysis. Ocul Surf 2018;16:173-9.

17. Stout NL, Alfano CM, Belter CW, et al. A Bibliometric Analysis of the Landscape of Cancer Rehabilitation Research (1992-2016). J Natl Cancer Inst 2018;110:815-24.

18. Durieux V, Gevenois PA. Bibliometric indicators: quality measurements of scientific publication. Radiology 2010;255:342-51.

19. Soteriades ES, Falagas ME. Comparison of amount of biomedical research originating from the European Union and the United States. BMJ 2005;331:192-4. 
20. Oelrich B, Peters R, Jung K. A bibliometric evaluation of publications in urological journals among European Union countries between 2000-2005. Eur Urol 2007;52:1238-48.

21. Garfield E. Journal impact factor: a brief review. CMAJ 1999;161:979-80.

22. Dasari S, Tchounwou PB. Cisplatin in cancer therapy: molecular mechanisms of action. Eur J Pharmacol 2014;740:364-78.

23. Swerdlow AJ, dos Santos Silva I, Reid A, et al. Trends in cancer incidence and mortality in Scotland: description and possible explanations. Br J Cancer 1998;77 Suppl 3:1-54.

24. Mortensen MS, Lauritsen J, Gundgaard MG, et al. A nationwide cohort study of stage I seminoma patients followed on a surveillance program. Eur Urol 2014;66:1172-8.

25. Xavier R, de Carvalho RC, Fraietta R. Semen quality from patients affected by seminomatous and non-seminomatous testicular tumor. Int Braz J Urol 2021;47:495-502.

26. Djaladat H, Burner E, Parikh PM, et al. The Association Between Testis Cancer and Semen Abnormalities Before Orchiectomy: A Systematic Review. J Adolesc Young Adult Oncol 2014;3:153-9.

27. Schrader M, Muller M, Straub B, et al. Testicular sperm extraction in azoospermic patients with gonadal germ cell tumors prior to chemotherapy--a new therapy option. Asian J Androl 2002;4:9-15.

28. Vasdev N, Moon A, Thorpe AC. Classification, epidemiology and therapies for testicular germ cell tumours. Int J Dev Biol 2013;57:133-9.

29. Horwich A, Shipley J, Huddart R. Testicular germ-cell cancer. Lancet 2006;367:754-65.

Cite this article as: Wang C, Tong L, Yao J, Sun Z, Zhang X, Liu T, Yin L. A bibliometric analysis of testicular germ cell tumor research from 2000 to 2020 . Transl Cancer Res 2021;10(8):3606-3618. doi: 10.21037/tcr-21-412
30. Heidenreich A, Paffenholz P, Nestler T, et al. Role of primary retroperitoneal lymph node dissection in stage I and low-volume metastatic germ cell tumors. Curr Opin Urol 2020;30:251-7.

31. de Vries G, Rosas-Plaza X, van Vugt MATM, et al. Testicular cancer: Determinants of cisplatin sensitivity and novel therapeutic opportunities. Cancer Treat Rev 2020;88:102054.

32. Tran V, Gibson L, Sengupta S. Retroperitoneal lymph node dissection for germ cell tumour. Transl Androl Urol 2020;9:3103-11.

33. Daneshmand S, Albers P, Fosså SD, et al. Contemporary management of postchemotherapy testis cancer. Eur Urol 2012;62:867-76.

34. Chen C. Searching for intellectual turning points: progressive knowledge domain visualization. Proc Natl Acad Sci U S A 2004;101 Suppl 1:5303-10.

35. Rapley EA, Turnbull C, Al Olama AA, et al. A genomewide association study of testicular germ cell tumor. Nat Genet 2009;41:807-10.

36. Wang Z, McGlynn KA, Rajpert-De Meyts E, et al. Metaanalysis of five genome-wide association studies identifies multiple new loci associated with testicular germ cell tumor. Nat Genet 2017;49:1141-7.

37. Litchfield K, Levy M, Huddart RA, et al. The genomic landscape of testicular germ cell tumours: from susceptibility to treatment. Nat Rev Urol 2016;13:409-19.

38. Bakardjieva-Mihaylova V, Skvarova Kramarzova K, Slamova M, et al. Molecular Basis of Cisplatin Resistance in Testicular Germ Cell Tumors. Cancers (Basel) 2019;11:1316. 